\title{
Uso e Benefício da Biologia Molecular nas Ciências Forenses e sua Aplicação no Banco de Perfis Genéticos
}

\author{
M.C. Santiago ${ }^{\text {a, }}$, B.O. Siqueira ${ }^{a}$, R.S.S. Barcelos ${ }^{b}$ \\ ${ }^{a}$ Pontificia Universidade Católica de Goiás (PUC GO) \\ ${ }^{b}$ Superintendência de Polícia Técnico Científica do Estado de Goiás (SPTC GO) \\ *Endereço de e-mail para correspondência:matheeuscavalcante@gmail.com .Tel:+55-62-984752611
}

Recebido em 15/11/2018; Revisado em 24/04/2020; Aceito em 14/06/2020

\begin{abstract}
Resumo
A biologia molecular no contexto forense é considerada uma poderosa ferramenta discriminatória, pois realiza diversos procedimentos em prol da integridade da amostra, refletindo em laudos precisos. A Lei 12.654/12 possibilitou a coleta de material genético de condenados por crimes hediondos ou de natureza grave contra a pessoa com a inserção dos perfis no banco de dados possibilitando identificar autores de crimes. O trabalho visa mostrar a importância do uso da biologia molecular no âmbito forense, os benefícios da aplicação da Lei, bem como a evolução e a contribuição do banco de dados de perfis genéticos no país, através de relatórios emitidos pela Rede Integrada de Banco de Perfis Genéticos (RIBPG). Para esta revisão bibliográfica foi realizada uma análise de periódicos nacionais e internacionais referentes as ciências forenses, genética forense e banco de dados de perfis genéticos. Embasamos na pesquisa a legislação pertinente e relatórios da RIBPG nos quais os dados foram compilados. Os relatórios demonstram o grande crescimento na inserção de perfis genéticos de todas as categorias. Dessa forma, observa-se o índice de resolução de crimes com indicação de autoria se tornando uma realidade nacional. A ferramenta mostrou ser indispensável na elucidação de crimes demonstrando avanços a nível molecular. A inserção desses perfis proporcionou aumento no número de investigações auxiliadas e coincidências entre os estados. Goiás, em cinco anos de participação, ocupa o quarto lugar nacional inserindo todas as categorias de perfis. Um laudo bem elaborado fortalece o processo judicial, auxilia no julgamento garantindo segurança e justiça no país.
\end{abstract}

Palavras-Chave: Lei 12.654/12, Banco de Dados de Perfis Genéticos; Ciências Forenses, RIBPG.

\begin{abstract}
Molecular biology in the forensic context is considered a powerful discriminatory tool, because it performs several procedures for the integrity of the sample, reflecting in accurate reports. Law 12.654/12 made it possible to collect genetic material from convicted felons for heinous crimes or serious crimes against the person with the insertion of the profiles in the database making it possible to identify perpetrators of crimes. The work aims to show the importance of the use of molecular biology in the forensic scope, the benefits of applying the Law, as well as the evolution and the contribution of the database of genetic profiles in the country, through reports issued by the Rede Integrada de Banco de Perfis Genéticos (RIBPG). For this bibliographic review, an analysis was made of national and international journals related to forensic science, forensic genetics and genetic profiling database. We base the pertinent legislation and reports of the RIBPG in which the data were compiled. The reports show the great growth in the insertion of genetic profiles of all categories. So, It is observed the index of resolution of crimes with indication of authorship becoming a national reality. The tool showed to be indispensable in the elucidation of crimes demonstrating advances at the molecular level. The insertion of these profiles provided an increase in the number of assisted investigations and coincidences between the states. Goiás, in five years of participation, occupies the fourth place national inserting all categories of profiles. A well-prepared report strengthens the judicial process, assists in the judgment guaranteeing security and justice in the country.
\end{abstract}

Keywords: Law 12.654/12, Genetic Profiles Databases; Forensic Science, RIBPG. 


\section{INTRODUÇÃO}

Com a descoberta da molécula de ácido desoxirribonucleico (DNA) foi possível sua utilização efetiva nas Ciências Forenses e na elucidação de crimes [1]. Por volta dos anos 80, Alec Jeffreys definiu um padrão genético específico e individual denominado DNA fingerprinting [2]. Com esta conquista, surgiram novas metodologias para amplificar a molécula, como a reação em cadeia da polimerase (PCR) que pode utilizar vários marcadores moleculares que auxiliam na identificação do autor [3]. A PCR traz como benefício a capacidade de analisar a molécula de DNA a partir de quantidades exíguas de amostras biológicas, como, por exemplo, em casos de células da mucosa oral deixada em uma guimba de cigarro ou fios de cabelos [4].

Esta metodologia contribuiu na elucidação de vários casos criminais, como exemplo, um caso de imigração na Inglaterra, criando uma nova esfera para as investigações, a genética forense. Desde então, com avanço da tecnologia, surgiram novos conceitos, metodologias e técnicas envolvidas na análise da molécula de DNA como ferramenta investigativa, principalmente no que diz respeito a sua manipulação [2].

\section{CIÊNCIAS FORENSES}

A análise de amostra biológica provinda de uma cena de crime precisa ser submetida a procedimentos técnicos, e ter a necessidade de cumprir várias normas éticas e de segurança para que não haja interferentes no decorrer da análise [5]. Diante disso, o profissional qualificado deve respeitar os padrões de biossegurança impostos na legislação vigente, utilizando seus equipamentos de proteção individual (EPIs), evitando sua exposição e a possível contaminação das evidências biológicas [6].

Para coleta destas evidências, cabe ao perito responsável respeitar e exigir o cumprimento de vários quesitos relacionados à preservação e seu manuseio. $\mathrm{O}$ isolamento de local de crime pode ser considerado como uma das partes primordiais e de grande relevância na obtenção das provas [7].

Evitar a violação e alteração da cena do crime passa a ser um desafio, pois parentes, curiosos e até mesmo autoridades policiais alteram o local, podendo ocasionar resultados não confiáveis inclusive com a possibilidade de mistura de material genético. $\mathrm{O}$ profissional designado para analisar cenas de crime é o Perito Criminal o qual está preparado para coletar diversos tipos de amostras utilizando um "kit de ferramentas" (swabs, seringas, pipetas pasteur, algodão, gazes, tubos com anticoagulantes, etc) $[7,8]$.

É importante frisar o manuseio e transporte de forma adequada, na qual, amostras úmidas requerem um procedimento de secagem para seu acondicionamento. Os microrganismos podem degradá-las interferindo na amplificação do material genético. Todas as amostras devem ser colocadas em recipientes separados, de preferência envelopes de papel, onde todos são obrigatoriamente identificados $[7,8]$.

Todas as evidências devem ser documentadas através de fotografias; a coleta realizada de forma adequada, lembrando que para cada tipo de material biológico necessita de padrão diferente de coleta; armazenadas em locais protegidos e sob refrigeração, se necessário; assim como registrar todos que tiveram contato com as evidências, de forma cronológica, preservando a respectiva cadeia de custódia [6]. Essa cadeia inclui o registro de toda sequência de posse e manuseio das evidências, desde o preparo do recipiente, coleta, transporte, recebimento, processamento, armazenamento e a respectiva expedição do laudo. Ou seja, todas as pessoas que participaram do processo de produção de provas serão incluídas na cadeia, seguindo a obrigatoriedade de se responder os seguintes questionamentos: quem, como e porque manuseou, onde o vestígio foi obtido, analisado, armazenado e a respectiva emissão do laudo [7-9].

Um dos benefícios alcançados ao realizar uma cadeia de custódia primorosa, consiste na melhor transparência das ações periciais, fazendo com que 
aumente a credibilidade e força para o julgamento. Qualquer falha na cadeia de custódia enfraquecerá o laudo, podendo ser a diferença entre o sucesso e o fracasso de uma condenação [10], conforme preconiza o Art. 170 do Código de Processo Penal - "Nas perícias de laboratório, os peritos guardarão material suficiente para a eventualidade de nova perícia. Sempre que conveniente, os laudos serão ilustrados com provas fotográficas, ou microfotográficas, desenhos ou esquemas" [11].

A amostra biológica questionada coletada em local de crime, a qual necessita de análise, passa por todo o procedimento já citado acima, ou seja, desde a coleta, transporte e o respectivo processamento em laboratórios oficiais. A análise obedece as seguintes fases: extração, quantificação, amplificação e corrida eletroforética, tudo sob um rígido controle de qualidade, além de uma equipe treinada e qualificada [10].

Para o processamento laboratorial dos inúmeros tipos de amostras questionadas, existem diversas metodologias de extração fundamentadas em biologia molecular, no sentido de obter o perfil genético a partir da utilização de marcadores moleculares situados tanto nos cromossomos autossômicos quanto sexuais [10]. Esses marcadores devem ser polimórficos, os quais proporcionam a obtenção de perfis genéticos específicos diferenciando a amostra da vítima e do suposto autor [12].

Após a amplificação da amostra, processa-se a etapa de quantificação da molécula de DNA utilizando a PCR em tempo real, o que torna possível uma melhor credibilidade da análise dessas evidências biológicas. Dessa forma se obtém uma estimativa precisa da sua concentração, criando a possibilidade de definir o método de análise mais efetivo, evitando procedimentos desnecessários [12].

Já na análise dos marcadores por PCR convencional utilizando sistema multiplex, a amplificação simultânea de vários loci torna-se possível. São usados com maior frequência marcadores do tipo microssatélite ou STR, os quais possuem sequências de nucleotídeos contendo de 1 a 5 pares de bases em seu comprimento.
Estes também apresentam alta taxa de mutação e um bom polimorfismo, com alto poder discriminatório sendo os mais utilizados em genética forense [13].

Quando na análise de marcadores microssatélites for empregado a utilização de monoplex, observa-se respostas que caracterizam um poder de discernimento bem menor, portanto, há a necessidade de se analisar um conjunto contendo vários loci de STR, e assim atingir resultados convincentes [13].

\section{BANCO DE DADOS}

Os perfis gerados em análises moleculares podem ser inseridos em softwares que armazenam uma base de dados às quais podem produzir respostas efetivas de confronto dessas informações. Existem vários bancos de dados a nível internacional que compilam essas informações e podem apresentar coincidências entre eles auxiliando nas investigações de crimes violentos [14,15].

A Inglaterra, pioneira na informatização de dados moleculares iniciou esse trabalho no ano de 1995 tendo sua lei aprovada com a coleta de material genético para identificação criminal em 2001. A legislação prevê a possibilidade de coleta do material genético para qualquer cidadão detido, favorecendo a polícia britânica ter uma maior liberdade para obter, utilizar e armazenar dados genéticos de sua população [16].

Os Estados Unidos da América também se destacou na investigação molecular desenvolvendo o sistema CODIS (Combined DNA Index System), criado na década de noventa, pelo FBI (Federal Bureau of Investigation). Possui um banco de perfis genéticos em nível nacional denominado NDIS (National DNA Index System) o qual foi legalizado no ano de 1994. Dessa forma o país conta com mais de 190 laboratórios oficiais fornecedores de dados de perfis genéticos. [17]

Esse sistema permite a comparação entre perfis genéticos oriundos de amostras encontradas em cenas de crimes, com amostras coletadas de criminosos, solucionando crimes. Dessa forma há correlação entre a amostra questionada e amostra referência. [14,15]. 
Já o Brasil utiliza o sistema informatizado e indexado de perfis de DNA cedido pelos Estados Unidos da América (CODIS). Inicialmente foram padronizados para análise do perfil genético nesse sistema, 13 loci de marcadores moleculares do tipo STR com alto polimorfismo, mostrados na Tab. 1. Todos os marcadores estão situados nos cromossomos autossômicos o que pode levar a uma individualização da amostra associados ao marcador amelogenina, situado nos cromossomos sexuais [7,14]. Em relação aos outros países o Brasil ainda permanece limitado em relação a legislação, a qual preconiza a coleta de material biológico e a inserção de perfil genético de indivíduos condenados por crimes dolosos, grave violência contra a pessoa e de caráter hediondo. Mesmo com essa limitação observa-se a elucidação de muitos crimes em várias unidades da federação, mas outras tipificações dos crimes ficam impossibilitadas de serem elucidadas com a investigação molecular [18].

Tabela 1: Marcadores moleculares padronizados pelo CODIS.

\begin{tabular}{l|c|c}
\hline NOME & LOCALIZAÇÃO & SEQUÊNCIA \\
\cline { 2 - 3 } CSF1PO & $5 \mathrm{q} 33.1$ & TAGA \\
FGA & $4 \mathrm{q} 31.3$ & CTTT \\
TH01 & $11 \mathrm{p} 15.5$ & TCAT \\
TPOX & $2 \mathrm{p} 25.3$ & GAAT \\
VWA & $12 \mathrm{p} 13.31$ & TCTG TCTA \\
D3S1358 & $3 \mathrm{q} 21.31$ & TCTG TCTA \\
D5S818 & $5 \mathrm{q} 23.2$ & AGAT \\
D7S820 & $7 \mathrm{q} 21.11$ & GATA \\
D8S1179 & $8 \mathrm{q} 24.13$ & TCTA TCTG \\
D13S317 & $13 \mathrm{q} 31.1$ & TATC \\
D16S539 & $16 \mathrm{q} 24.1$ & GATA \\
D18S51 & $18 \mathrm{q} 21.33$ & AGAA \\
D21S11 & $21 \mathrm{q} 21.1$ & TCTA TCTG \\
\hline
\end{tabular}

\section{REDE INTEGRADA DE BANCO DE PERFIS GENÉTICOS NO BRASIL}

A Lei $12.654 / 2012$ foi editada proporcionando a identificação molecular de indivíduos condenados havendo a inserção dos resultados em um banco de dados. Para uma maior organização a nível nacional houve a criação da Rede Integrada de Banco de Perfis Genéticos (RIBPG) e do Banco Nacional de Perfis Genéticos (BNPG) no ano de 2009. Sua regulamentação ocorreu através do Decreto $\mathrm{n}^{\circ} 7.950$ de 2013, no âmbito do Ministério da Justiça, predizendo a adesão das Unidades Federativas à RIBPG através de assinatura de um acordo de Cooperação Técnica $[19,20]$.

Para padronização de procedimento nesse mesmo Decreto houve a criação de um comitê gestor que orientou as etapas necessárias para a coleta, análise, armazenamento, manuseio e a respectiva inclusão dos perfis genéticos nos bancos de dados da RIBPG. Assim, os direitos individuais foram garantidos juntamente com a confiabilidade e o sigilo dos dados. O objetivo de se implantar o banco se deu em função de contribuir na elucidação de crimes, identificar pessoas desaparecidas e rever condenações [20].

Os dados obtidos nesses procedimentos podem ser inseridos na RIBPG sendo provenientes das análises das amostras biológicas deixadas na cena de crime ou no corpo da vítima, bem como, nos vestígios processados. Esses resultados devem ser confrontados entre si, e comparados com os dados de indivíduos condenados criminalmente conforme a Lei $\mathrm{n}^{\circ} 12.654 / 2012$, citada anteriormente [18,20-30].

Essa Lei foi editada em 28 de maio de 2012 a qual complementou a Lei 12.037/2009 que dispõe sobre os processos datiloscópico e fotográfico como métodos de identificação criminal. Para melhorar esse processo houve a autorização da coleta de material biológico, por método indolor, utilizando swab de mucosa oral. Nessa metodologia há a obtenção de um perfil genético dos indivíduos condenados contra crimes dolosos, com grave violência contra a pessoa e crimes hediondos, tentados ou 
consumados [18,31]. Foi regulamentado que a análise molecular do material deve utilizar a região não codificante da molécula do DNA, pois há vedação da revelação de traços somáticos ou comportamentais da pessoa, com exceção de marcadores que identificam o gênero sexual [20-30].

A coleta do material genético mediante autorização judicial pode ser realizada na fase da investigação policial. Após o processamento do exame, o perfil genético obtido só pode ser inserido no banco de dados após a avaliação das condições constantes no Decreto $n^{\circ}$ 7.950/2013. A inserção dos resultados deve ser realizada por peritos oficiais de natureza criminal habilitados e aprovados pelas unidades federativas das regiões signatárias. Em contrapartida, ressalta a necessidade de excluir as informações contidas nos bancos de dados ao final do prazo prescricional do crime investigado [32].

O software possui pastas específicas tais como, vestígios, condenados, identificados criminalmente e decisão judicial. Dessa forma após a inserção do perfil, há uma busca dessas informações no servidor estadual e no nacional em busca de coincidências. Portanto, esses resultados podem ser confrontados através desse sistema com os dados genéticos de todos os estados que integram a RIBPG proporcionando coincidência (match) entre as amostras [20-30].

Os dados integralizados no sistema são apresentados em relatório elaborado pela RIBPG, semestralmente, e publicados no sítio do Ministério da Justiça, nos meses de maio e novembro. A seguir, apresentamos a compilação dos dados referentes ao trabalho executado nos anos de 2014 a 2019.
Observamos, na Tab. 2, um aumento gradual no número de perfis genéticos inseridos no banco a cada ano de trabalho das equipes que compõem a rede. Nota-se uma maior inserção da categoria vestígios, pois as unidades policiais diuturnamente estão em contato com locais de crime, onde são colhidos os vestígios e encaminhados para análise nos laboratórios oficiais.

$\mathrm{Na}$ categoria "condenados" observa-se um aumento, até maio de 2018, na inserção desses perfis após a edição da lei 12.654/2012. Observa-se também que entre os anos de 2018 e 2019 houve um aumento considerável de perfis inseridos no banco. Esse resultado foi fruto do esforço de todos os laboratórios oficiais de todas as unidades da federação. Essa melhoria se deve a implantação de mais laboratórios oficiais no país aliado ao grande esforço das equipes no sentido de coletar, analisar e inserir os resultados no banco de dados.

Contrariando os dados apresentados nas duas categorias acima mencionadas, a dos indivíduos identificados criminalmente mostra um menor aumento em relação às demais. Isso se deve ao fato de a autoridade policial muitas vezes não solicitar ao juiz a identificação genética durante a investigação.

Já a categoria intitulada Decisão judicial apresenta uma ínfima quantidade de perfis inseridos no início dos trabalhos, a qual pode ser explicada pelo fato da necessidade de uma maior divulgação entre as autoridades judiciais. À medida que os resultados do banco de dados foram sendo evidenciados observou-se que os resultados de maio a novembro, nessa categoria, cresceram o dobro, mostrando o crescimento das autorizações judiciais fortalecendo, também o banco de dados.

Tabela 2: Quantidade de Perfis Genéticos oriundos de amostras relacionados a casos criminais inseridos por categoria nos anos de 2014 a 2019 , no Brasil.

\begin{tabular}{|l|c|c|c|c|c|c|c|c|c|c|c|}
\hline \multirow{2}{*}{ Categorias } & $\mathbf{2 0 1 4}$ & \multicolumn{2}{|c|}{2015} & \multicolumn{2}{c|}{$\mathbf{2 0 1 6}$} & \multicolumn{2}{c|}{$\mathbf{2 0 1 7}$} & \multicolumn{2}{c|}{2018} & \multicolumn{2}{c|}{2019} \\
\cline { 2 - 13 } & Nov & Mai & Nov & Mai & Nov & Mai & Nov & Mai & Nov & Mai & Nov \\
\hline Vestígios & 1524 & 1967 & 2647 & 3423 & 4298 & 4971 & 5925 & 6805 & 7872 & 9111 & 10515 \\
\hline Condenados & 53 & 569 & 753 & 955 & 1283 & 1687 & 2008 & 3269 & 6536 & 17361 & 54657 \\
\hline Identificados Criminalmente & 26 & 38 & 62 & 95 & 108 & 148 & 208 & 355 & 441 & 545 & 684 \\
\hline Decisão Judicial & 1 & 1 & 4 & 4 & 8 & 10 & 12 & 10 & 73 & 167 & 337 \\
\hline Total & 1604 & 2575 & 3466 & 4477 & 5697 & 6816 & 8153 & 10439 & 14922 & 27184 & 66193 \\
\hline
\end{tabular}


Na comunidade jurídica há a existência de um dilema o qual gera um debate em relação à aplicabilidade da Lei 12.654/2012. Na doutrina em geral, há um afrontamento do princípio da não autoincriminação, ou seja, que o cidadão não pode ser obrigado a produzir prova contra si, conforme preconiza em seu artigo 5 , podendo haver questionamento sobre sua inconstitucionalidade. Em contrapartida há juristas que a defendem, reconhecendo como um meio necessário e determinante para uma justiça mais efetiva e acurada [33-35].

No banco de perfis genéticos há também uma categoria destinada a inserção de dados genéticos em relação a pessoas desaparecidas, informações essas não apresentadas na tabela. Nessa categoria incluem os perfis genéticos dos familiares, de restos mortais não identificados e pessoas vivas com identidade desconhecida, além da referência direta. Este fato auxilia em investigações com a possibilidade de responder às famílias que buscam parentes desaparecidos, confrontando os dados genéticos com intuito de se encontrar um match e, finalmente, acabar com a aflição deles [20].

A Tabela 3 apresenta as categorias coincidências confirmadas e auxílio em investigações que mostram os resultados compilados pela RIBPG no Brasil nos anos de 2014 a 2019. As coincidências confirmadas inseridas no banco de dados (confronto entre vestígios ou entre vestígio e identificados criminalmente) mostram que o trabalho das equipes dos laboratórios oficiais policiais permanece muito determinado, pois a cada relatório apresentado a quantidade de respostas se torna mais efetiva.

Já a categoria auxílio em investigações também demonstra resultados positivos e crescentes ao longo dos anos. Esses resultados irão subsidiar o laudo pericial fortalecendo o processo investigativo com uma prova material robusta. Baseado nestas informações é possível consolidar a real contribuição dos bancos de perfis genéticos no cenário judicial brasileiro, proporcionando a identificação da autoria do delito.

O Gráfico 1 demonstra uma curva crescente da taxa de coincidências entre os anos de 2014 a 2019 à medida que mais laboratórios oficiais participam da RIBPG. Assim, observa-se uma qualificação das investigações criminais, pois o compartilhamento dos dados possibilita respostas mais efetivas com maior número de match, ou seja, coincidências de perfis de suspeitos e vestígios dentre e entre estados desde a sua implantação [20-30].

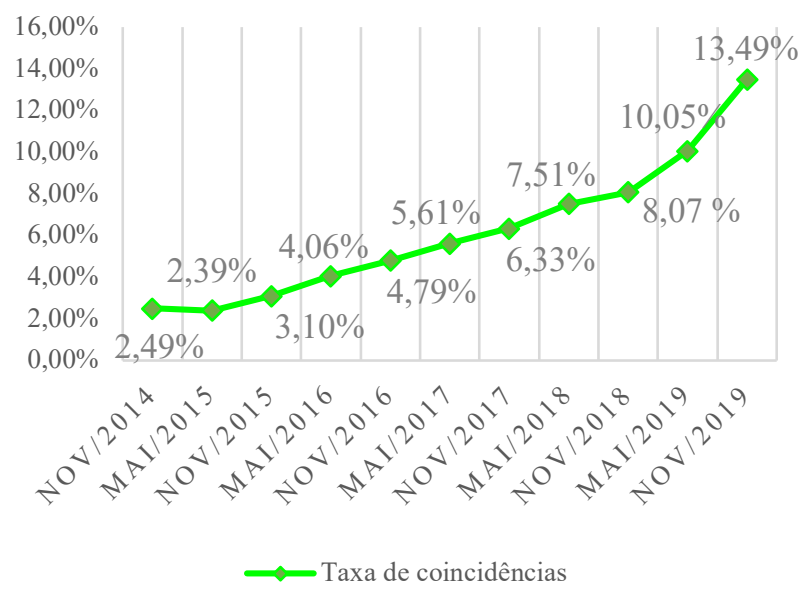

Gráfico 1: O crescimento gradual da taxa de coincidências nos anos de 2014 a 2019.

O progresso dos resultados do banco de perfis genéticos no país só foi observado em função da abertura de mais laboratórios oficiais de genética forense em várias unidades federativas entre os anos de 2014 a 2019 (Gráf. 2). Nota-se que a participação de novos estados precede de treinamento, experiência mínima na emissão de laudos forenses, e a exigência de uma série de condutas e restrições para a inclusão dos perfis genéticos. Comparando o início da rede no Brasil com 15

Tabela 3: Quantidade de coincidências confirmadas e de auxílio em investigações no Brasil de 2014 a 2019 nos meses de maio e novembro.

\begin{tabular}{|c|c|c|c|c|c|c|c|c|c|c|c|}
\hline \multirow{2}{*}{ Categorias } & 2014 & \multicolumn{2}{|c|}{2015} & \multicolumn{2}{|c|}{2016} & \multicolumn{2}{|c|}{2017} & \multicolumn{2}{|c|}{2018} & \multicolumn{2}{|c|}{2019} \\
\hline & Nov & Mai & Nov & Mai & Nov & Mai & Nov & Mai & Nov & Mai & Nov \\
\hline Coincidências Confirmadas & 38 & 47 & 82 & 139 & 206 & 279 & 376 & 551 & 635 & 926 & 1418 \\
\hline Auxílio em Investigações & 71 & 91 & 148 & 206 & 351 & 372 & 436 & 561 & 559 & 852 & 1060 \\
\hline
\end{tabular}




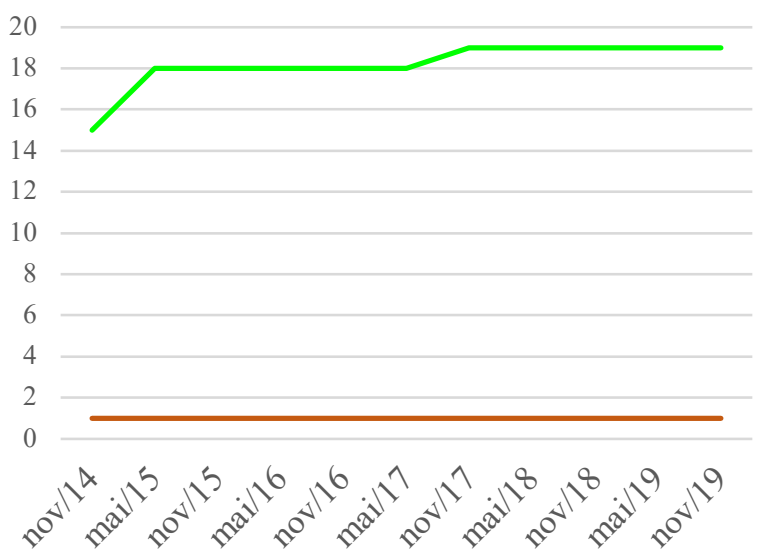

Laboratórios estaduais Laboratórios federais

Gráfico 2: Participação dos laboratórios na RIBPG nos anos de 2014 a 2019.

laboratórios estaduais e 1 federal integrados, e com a incorporação de mais 4 estaduais, um notório desenvolvimento do banco foi observado (20-30).

Até o presente momento estão participando da RIBPG dezoito estados brasileiros: Amazonas, Amapá, Bahia, Ceará, Espírito Santo, Goiás, Maranhão, Minas Gerais, Mato Grosso do Sul, Mato Grosso, Pará, Paraíba, Pernambuco, Paraná, Rio de Janeiro, Rio Grande do Sul, Santa Catarina, São Paulo, além do Distrito Federal e o laboratório da Polícia Federal. Para que haja uma maior participação de estados brasileiros no banco de perfis genéticos, o Ministério da Justiça e Segurança Pública tem incentivado a todos a iniciarem os projetos de implantação dos laboratórios de genética forense. Atualmente todos os estados brasileiros já possuem laboratórios de genética forense em funcionamento e em breve todos estarão compartilhando perfis genéticos na RIBGP [20-30].

A Figura 1 ilustra as unidades federativas brasileiras que já pertencem a RIBPG e as que estão em processo de admissão até o presente momento. Portanto, observa-se que faltam poucos estados brasileiros para ter a integração total no país, sendo possível presumir isto em um futuro próximo [30].

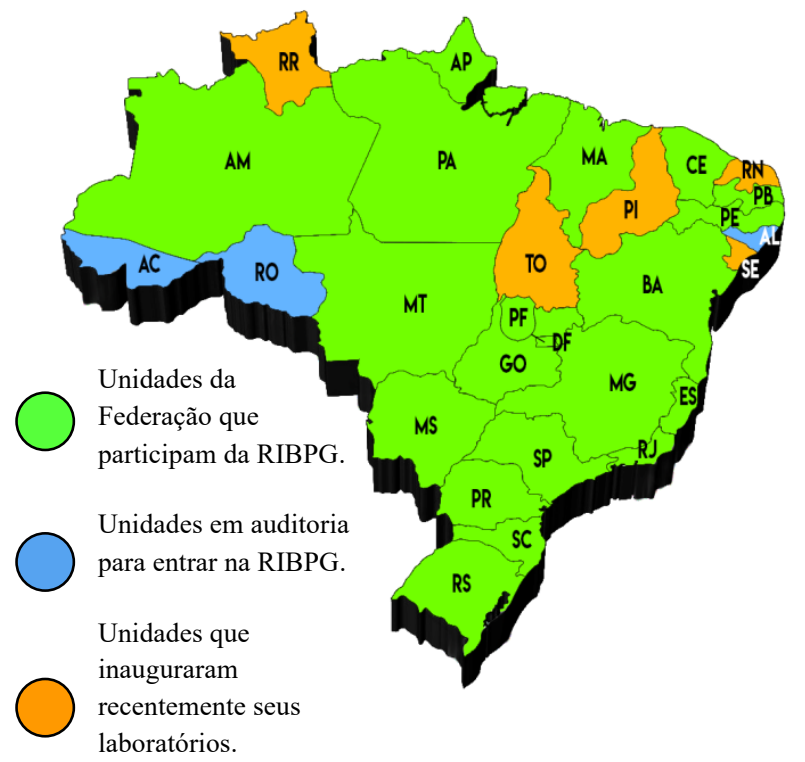

Figura 1: Unidades federativas brasileiras pertencentes e em processo de admissão na RIBPG.

O banco regional de perfis genéticos iniciou no estado de Goiás em maio de 2015 sendo integrado aos estados já participantes da RIBPG. A integração beneficia a resolução de crimes, pois pode relacionar casos ocorridos em locais e em épocas distintas, bem como proporcionar a elucidação de crimes sem suspeito. Podemos citar, como exemplo, um caso antigo do ano de 2014 onde houve uma ocorrência de danos ao patrimônio seguido de estupro em um município próximo a Capital. Nesse caso foi coletada amostra de sêmen no banheiro e encaminhada ao Laboratório de Biologia e DNA Forense (LBDF) da Superintendência de Polícia TécnicoCientífica de Goiás (SPTC/GO), analisado e expedido um laudo com a conclusão de inclusão do suspeito. O perfil genético obtido dessa amostra foi então inserido no Banco de Perfis Genéticos da SPTC [25].

Dois anos depois houve um caso de sequestro a um gerente de uma agência dos Correios na cidade de Ponte Alta do Bom Jesus/TO. No local do crime foi coletada uma guimba de cigarro, que foi analisada no Laboratório de DNA Forense da Polícia Federal. Não foi apresentado nenhum suspeito pela investigação, mas o perfil obtido na análise do vestígio foi inserido no banco de perfis genéticos da Polícia Federal (PF). Após uma busca realizada no BNPG houve uma coincidência entre os perfis genéticos obtidos do sêmen analisados pela 
perícia oficial de Goiás com o da guimba coletada e analisada pela PF identificando assim, o autor. Esse exemplo mostra a contribuição do BNPG no auxílio e na elucidação de um caso ainda sem suspeito, bem como na resolução de casos antigos e o compartilhamento de dados moleculares interestaduais [25].

Esses resultados só foram possíveis após o convênio firmado para a implementação do banco de perfis genéticos no Brasil, observando-se um incremento na inserção dos perfis, bem como, a incorporação de mais laboratórios. Goiás vem demonstrando resposta efetiva contribuindo para elucidação de crimes tanto no estado quanto interestaduais. Atualmente, observando os dados publicados observa-se que o estado ocupa o $4^{\circ}$ lugar no ranking nacional em investigações auxiliadas e coincidências confirmadas. Outro dado que se destaca no estado é a inserção de todas as categorias de perfis genéticos (vestígios de crime, condenados, suspeitos e legal, restos mortais não identificados, identidade desconhecida, referência direta e indireta de pessoa desaparecida) [36].

Neste período o laboratório de perícia criminal de Goiás inseriu um total de 620 perfis genéticos no banco, onde destes, 313 são de condenados e 247 de vestígios coletados em locais de crime. Mota \& Finotti [36] apontam que $87 \%$ dos vestígios inseridos são originados de crimes sexuais e que esses perfis no banco auxiliaram 38 investigações dentro do estado e 12 interestaduais. Tais resultados demonstram a reincidência deste tipo de crime, principalmente quando não há condenação e sua respectiva pena aos agressores [36].

Os resultados apresentados acima são positivos e entusiasmantes para o Brasil que fortalece essa metodologia mesmo tendo países como Estados Unidos e Inglaterra os quais possuem um sistema judicial que possibilita a inserção de outras categorias com resultados muito acima do apresentado em nosso país. Conforme já destacado acima, estes países possuem uma lei mais ampla, aliado a um sistema informatizado de perfis genéticos há mais tempo proporcionando resultados mais efetivos e, por conseguinte, melhor aceitação no judiciário [36].

\section{CONCLUSÃO}

A institucionalização da RIBPG possibilitou a inserção de perfis de condenados contra crimes dolosos, grave violência contra a pessoa e hediondos, viabilizando a comparação em bancos estaduais e o nacional. Com isso, houve a possibilidade de inúmeras coincidências entre perfis que favoreceram a indicação de autoria. Dessa forma, o governo federal proporcionou incentivos e investimentos em unidades da federação que ainda não estavam inseridas na RIBPG expandindo o número de laboratórios participantes, proporcionando a inserção de mais perfis genéticos, aumentando a taxa de coincidências. Observou-se também, uma evidente necessidade de integração das equipes envolvidas na investigação para a obtenção de resultados robustos.

Com esses resultados observados verifica-se a importância da manutenção do banco de perfis genéticos no país, bem como o avanço nas técnicas investigativas tradicionais que necessitavam da apresentação de um suspeito pela autoridade policial para o respectivo exame de confronto molecular e a possível conclusão da investigação. O exercício da justiça se torna eficaz e robusto, com possibilidade do aumento da pena diminuindo a impunidade no país. Portanto, o banco de perfis genéticos contribui para uma melhor sensação de segurança e justiça.

\section{REFERÊNCIAS}

[1] A. Zaha; H.B. Ferreira; L.M.P. Passaglia. Biologia molecular básica. $5^{\mathrm{a}}$ ed. Porto Alegre: ArtMed, 2014.

[2] A. Jeffreys; V. Wilson; S. Thein. Hypervariable "minisatellite" regions in human DNA. Nature, 314, p. 67-73, 1985 .

[3] K. Mullis; F. Faloona; S. Scharf ; et al. Specific Enzymatic Amplification of DNA In Vitro: The Polymerase Chain Reaction. Cold Spring Harb Symp 
Quant Biol, 51, p. 263-273, 1986.

[4] C.J.F. Gaertner; P. Binsfeld. Técnicas de Biologia Molecular aplicadas na Investigação Forense. p. 1-6, 2011

[5] S.D.J. Pena. Segurança pública: Determinação de identidade genética pelo DNA, Parcerias estratégicas, 2005.

[6] V.S. Leite; et al. Uso Das Técnicas De Biologia Molecular $\mathrm{Na}$ Genética Forense. Derecho y Cambio Social. p. 1-18, 2013.

[7] J.M. Sousa; P.R.M. Queiroz. Coleta e preservação de vestígios biológicos para análises criminais por DNA. Ensaios e Ciência: Ciências Biológicas, Agrárias e da Saúde. Campo Grande, v. 16, n. 3, p. 99-115, 2012.

[8] Secretaria Nacional de Segurança Pública. Procedimento operacional padrão (POP) - Perícia Criminal. 2013.

[9] P. Dariva. A cadeia de custódia da prova genética. Dissertação (Mestrado em Ciências Criminais) Faculdade de Direito, Pontifícia Universidade Católica do Rio Grande do Sul, Porto Alegre. 2015.

[10] N.S. Bonaccorso. Aplicação do exame de DNA na elucidação de crimes. Dissertação (Mestrado em Medicina Forense) - Faculdade de Direito, Universidade de São Paulo, São Paulo. 2005.

[11] BRASIL. Decreto-Lei no 3.689, de 3 de outubro de 1941. Retirado em 05 de junho de 2018, de: http://www.planalto.gov.br/ccivil_03/decretolei/Del3689.htm.

[12] C.A.P. Martins. Quantificação de DNA por PCR em Tempo Real em diferentes Amostras Forenses. 2016. Dissertação (Mestrado em Ciências Forenses) Universidade do Porto, Porto.

[13] D. Decanine. O papel de marcadores moleculares na genética forense. Revista Brasileira de Criminalística, v. 5, n. 2, p. 18-27, 2016.

[14] R.G. G arrido; E.L. Rodrigues. O Banco de Perfis Genéticos Brasileiro três anos após a Lei $\mathrm{n}^{\mathrm{o}} 12.654$. Revista de Bioética y Derecho, p. 94-107, 2015.

[15] T.F. Cavalcante; P.R. Queiroz. Banco de Dados Baseado em Marcadores Genéticos. $8^{a}$ Mostra de produção científica da pós-graduação Lato sensu da PUC Goiás. Goiânia, 2013

[16] P.D. Martin; H. Schmitter; P.M. Schneider. A brief history of the formation of DNA databases in forensic science within Europe. Forensic Science International. v. 119 , n. 2, p. 225-231, 2001.

[17] FBI. Combined DNA Index System (CODIS).

U.S. Department of Justice. Disponível em:

https://www.fbi.gov/services/laboratory/biometricanalysis/codis. Acesso em 05 de maio de 2020.

[18] BRASIL. Lei $n^{\circ}$ 12.654, de 28 de maio de 2012. Retirado em 08 de junho de 2018, de http://www.planalto.gov.br/ccivil_03/_Ato2011-

2014/2012/Lei/L12654.htm

[19] D. Marion. Banco de dados de perfis genéticos e sua aplicabilidade na produção da prova nos crimes dolosos contra a vida e contra a dignidade sexual: uma forma de evitar a reincidência e solucionar "cold cases". Trabalho de Conclusão de Curso (Graduação de Direito) Universidade de Santa Cruz do Sul, Santa Cruz do Sul, 2017.

[20] BRASIL. I Relatório da rede integrada de bancos de perfis genéticos - Dados estatísticos e resultados relativos a novembro de 2014. Ministério da Justiça e Cidadania, 2014.

[21] BRASIL. II Relatório da rede integrada de bancos de perfis genéticos - Dados estatísticos e resultados relativos a maio de 2015. Ministério da Justiça e Cidadania, 2015.

[22] BRASIL. III Relatório da rede integrada de bancos de perfis genéticos - Dados estatísticos e resultados relativos a novembro de 2015. Ministério da Justiça e Cidadania, 2015

[23] BRASIL. IV Relatório da rede integrada de bancos de perfis genéticos - Dados estatísticos e resultados relativos a 28 de maio de 2016. Ministério da Justiça e Cidadania, 2016.

[24] BRASIL. V Relatório da rede integrada de bancos de perfis genéticos - Dados estatísticos e resultados relativos a 28 de novembro de 2016. Ministério da Justiça e Cidadania, 2016 
[25] BRASIL. VI Relatório da rede integrada de bancos de perfis genéticos - Dados estatísticos e resultados relativos a 28 de maio de 2017. Ministério da Justiça e Cidadania, 2017.

[26] BRASIL. VII Relatório da rede integrada de bancos de perfis genéticos - Dados estatísticos e resultados relativos a 28 de novembro de 2017. Ministério da Justiça e Cidadania, 2017.

[27] BRASIL. VIII Relatório da rede integrada de bancos de perfis genéticos - Dados estatísticos e resultados relativos a 28 de maio de 2018. Ministério da Justiça e Cidadania, 2018.

[28] BRASIL. IX Relatório da rede integrada de bancos de perfis genéticos - Dados estatísticos e resultados relativos a 29 de novembro de 2018. Ministério da Segurança Pública, 2018.

[29] BRASIL. X Relatório da rede integrada de bancos de perfis genéticos - Dados estatísticos e resultados relativos a maio de 2019. Ministério da Justiça e Segurança Pública, 2019.

[30] BRASIL. XI Relatório da rede integrada de bancos de perfis genéticos - Dados estatísticos e resultados relativos a novembro de 2019. Ministério da Justiça e Segurança Pública, 2019.

[31] BRASIL. Lei 12.037, de $1^{\mathrm{o}}$ de outubro de 2009. Retirado em 08 de junho de 2018, de http://www.planalto.gov.br/ccivil_03/_Ato2007-

2010/2009/Lei/L12037.htm

[32] BRASIL. Decreto no 7.950, de 12 de março de 2013. Retirado em 15 de julho de 2018, de http://www.planalto.gov.br/ccivil_03/_Ato20112014/2013/Decreto/D7950.htm

[33] M.C.S. Silva. Investigação criminal e banco de dados genéticos. Revista de Artigos cientificos dos Alunos da EMERJ. v. 9, n. 1, p. 638-655. Rio de Janeiro, 2013.

[34] N.F.L. Tavares; R.G. Garrido; A.E.R. Santoro. O banco de perfis genéticos e a estigmatização perpétua: uma análise do Art. 9 ${ }^{\circ}$-A da Lei 7.210/84 à luz da criminologia crítica. Revista Jurídica. v. 4, n. 45, p.207226, Curitiba, 2016.

[35] BRASIL. Ministério Público Federal. Do parecer no tocante ao Recurso extraordinário com repercussão geral reconhecida. Coleta de perfil genético para fins de identificação criminal. Ausência de ofensa aos artigos $1^{\circ}$ III e 5'-II, X, LIV e LXIII da constituição Federal. Parecer $n^{\circ}$ 07/2017 - AJCR/SGJ/PGR de 18 de dezembro de 2017. Relator: Ministro Gilmar Mendes. ProcuradoriaGeral da República. Brasília.

[36] M.F. Mota; N.C.P. Finotti. Contribuição do Banco de Perfis Genéticos da Superintendência de Polícia TécnicoCientífica do Estado de Goiás com a elucidação de crimes após três anos de funcionamento. Revista Brasileira de Criminalística. v. 7, n.1, p. 26-31, 2018. 